\title{
Change in Site of Children's Primary Care: A Longitudinal Population-Based Analysis
}

\author{
Richard C. Wasserman, MD, MPH \\ Susan E. Varni, PbD \\ Matthew C. Hollander, MD, MHA \\ Valerie S. Harder, PbD, MHS \\ The Robert Larner, MD College of Medi- \\ cine, University of Vermont, Burlington, \\ Vermont
}

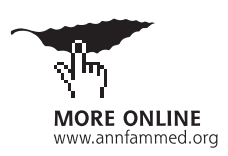

Conflicts of interest: authors report none.

\section{CORRESPONDING AUTHOR}

Richard C. Wasserman, MD, MPH

1 South Prospect Street

St Joseph 7203

Burlington, VT 05401

Richard.Wasserman@med.uvm.edu

\begin{abstract}
PURPOSE Evidence that fewer children are being seen at family physician (FP) practices has not been confirmed using population-level data. This study examines the proportion of children seen at FP and pediatrician practices over time and the influence of patient demographics and rurality on this trend.
\end{abstract}

METHODS We conducted a retrospective longitudinal analysis of Vermont allpayer claims (2009-2016) for children aged 0 to 21 years. The sample included 184,794 children with 2 or more claims over 8 years. Generalized estimating equations modeled the outcome of child attribution to a FP practice annually, with covariates for calendar year, child age, sex, insurance, and child Rural Urban Commuting Area (RUCA) category.

RESULTS Over time, controlling for other covariates, children were $5 \%$ less likely to be attributed to a FP practice $(P<.001)$. Children had greater odds of attribution to a FP practice as they aged (odds ratio $(\mathrm{OR})=1.11,95 \% \mathrm{Cl}, 1.10-1.11$ ), if they were female $(\mathrm{OR}=1.05,95 \% \mathrm{Cl}, 1.03-1.07)$ or had Medicaid $(\mathrm{OR}=1.09$, $95 \% \mathrm{Cl}, 1.07-1.10)$. Compared with urban children, those from large rural cities $(\mathrm{OR}=1.54,95 \% \mathrm{Cl}, 1.51-1.57)$, small rural towns $(\mathrm{OR}=1.45,95 \% \mathrm{Cl}, 1.42-1.48)$, or isolated/small rural towns (OR $=1.96,95 \% \mathrm{Cl}, 1.93-2.00$ ) had greater odds of FP attribution. When stratified by RUCA, however, children had 3\% lower odds of attending a FP practice in urban areas and $8 \%$ lower odds in isolated/small rural towns.

CONCLUSIONS The declining proportion of children attending FP practices, confirmed in this population-based analysis and more pronounced in rural areas, represents a continuing challenge.

Ann Fam Med 2019;17:390-395. https://doi.org/10.1370/afm.2416.

\section{INTRODUCTION}

The overwhelming majority of US children are seen for primary care by family physicians (FPs) and pediatricians (PEDs). ${ }^{1}$ Studies suggest, however, that the proportion of children seeing FPs has been decreasing..$^{2-5}$ This trend is significant for several reasons. First, family medicine and primary care pediatrics represent different approaches to care, offering families different areas of expertise. Second, if FPs are seeing fewer children over time, the concept of family medicine as a discipline serving entire families becomes problematic, calling for careful reconsideration of how the discipline is described. ${ }^{1,3}$ Third, insofar as FPs and PEDs are not evenly spread geographically, ${ }^{6}$ with marked disparities in access within states, such a trend could be worsening health care disparities. Fourth, fewer children seen in FP practices would mean more children would need to transition from pediatric-only to adult-oriented care. Such transitions are challenging, especially for youth with chronic health problems. ${ }^{7}$ Finally, to the extent that workforce policy affects the distribution of clinicians, policy makers' understanding of this shift has implications for future physician training and practice sustainability.

Our understanding of trends in the decreasing proportion of children seeing FPs has not been confirmed on a population basis and is grounded 
solely in surveys: serial cross-sectional surveys of patient visits, ${ }^{8}$ and physician-reported data from the American Board of Family Medicine recertification surveys. It is important, therefore, to confirm the shift in proportion of children seeking primary care from FPs to PEDs at the population level. Vermont represents an excellent testing ground for exploring FP/ PED trends-especially with respect to the geographic distribution of clincians. The Vermont Health Care Uniform Reporting \& Evaluation System ${ }^{9}$ is an allpayer claims database. It is not subject to the sampling and incomplete response bias present in the National Ambulatory Medical Care Survey methodology or the self-report bias of the American Board of Family Medicine recertification surveys, and it offers patient-level longitudinal data of utilization. Also, the highly rural state of Vermont has an ample per capita supply of both FPs and PEDs, ${ }^{6,10,11}$ but also has $25 \%$ of its child population living in rural areas with a low supply of physicians trained to care for children. ${ }^{6,12}$ This demographic situation provides the opportunity to address rural residence as a factor in the site of primary care for children.

The objectives of this study were to test, based on Vermont claims data, (1) whether the proportion of children at the population level seen at FP and PED practices is changing over time, (2) how this change is influenced by patient demographics (age, sex, rurality, insurance), and (3) whether these associations vary by the rurality of patient residence.

\section{METHODS}

\section{Data and Population}

The study team accessed the Vermont Health Care Uniform Reporting \& Evaluation System for services provided from January 1, 2009 through December 31, 2016. Our sample contained claims for visits for all children (aged 0 to 21 years) with a reported service, physician, and home zip code in Vermont enrolled in any health plan including commercial health plans, Medicaid, and Medicare. Our study population began with 309,722 children with at least 1 claim during 2009-2016. Of those, 198,562 children were attributed to a FP or PEDS practice. The final sample was limited to 184,794 children having at least 2 years with claims during the 8 year period.

\section{Attribution Methodology}

We used a hierarchical approach to attribute children to primary care clinicians (physicians, nurse practitioners, or physician assistants) each year based on services children received, similar to previous work by Christensen and colleagues. ${ }^{13}$ Visits were classi- fied using Current Procedural Terminology codes and International Classification of Diseases Clinical Modification codes (version 9 before October 2015, and version 10 thereafter , see Supplemental Table at http://www.annfammed.org/content/17/5/390/suppl/ DC1). Children were attributed to primary care clinicians who provided all or the majority of the well-child visits. If a child had no well-child visits, they were attributed to the clinician for all or the majority of specific ambulatory visits including evaluation and management visits and other preventive visits, such as vision and hearing screening. If a child was still unattributed at this point, they were attributed to the PED or FP primary care clinician who provided the majority of the child's care for any reason (ie, visits could have any of the Current Procedural Terminology or International Classification of Diseases Clinical Modification codes not used in the previous steps). Any remaining children were attributed to the clinician they had seen most often, most recently.

Because the Vermont Health Care Uniform Reporting \& Evaluation System does not contain fields linking all clinicians with their practice or organization, we developed procedures for matching the clinician on a child's medical claim with a practice or organization historically, for each year. We used various state and public resources including Vermont's health care reform program, the Vermont Blueprint for Health, and the Vermont Area Health Education Centers. The Vermont Department of Health also conducts a census of selected health care professionals that includes practice locations and time spent by clinicians at each location. The Department of Vermont Health Access (Medicaid) maintains a list of active Medicaid providers. In addition to these resources, we contacted the largest private insurance provider in Vermont for in-network clinicians and their practice information, and consulted practice websites, practice and organization press releases and newsletters, and commercial websites with clinician information to confirm when clinicians may have joined or left a practice. Finally, we contacted practices by e-mail and telephone to verify dates of service for some clinicians. When possible, clinicians were associated with the practice where they spent the majority of their time in a calendar year. In cases where a clinician appeared in medical claims in 1 year but not in following years, only in later years, or intermittently over many years, the clinician's history of practice in Vermont was verified.

\section{Statistical Analyses}

Analyses included the years 2009-2016, child age modeled as a continuous variable, and sex as binary female 
vs male, and children with any Medicaid product were classified as having Medicaid as a binary variable. Rural geographic location was categorized by linking children's home zip code to the modified Rural Urban Commuting Area (RUCA) classification system. RUCA categories were assigned to zip codes and incorporated commuting data from census tracts into their criteria. ${ }^{14}$ The analysis used the 4-tier consolidation (urban, large town, small town, and isolated rural) of the original RUCA classification system. ${ }^{15,16}$

To address study objectives 1 and 2, longitudinal multiple regression analyses including 8 years of data were conducted using a generalized estimating equation statistical model. The generalized estimating equation model was expanded to examine the moderating effect of rurality (RUCA category) on the associations between all covariates and the site of primary care practice type to address objective 3 . Interaction terms between RUCA category and covariates were added to the above generalized estimating equation model, first to test for significant interactions, and then the model was stratified into the 4 RUCA categories to explore effects within geographic regions. All statistical analyses were conducted in Stata SE version 15 (StataCorp LLC) statistical software and associations were considered statistically significant at $P<.05$.

The scope of work for this study was approved by the Institutional Review Board at the University of Vermont and by the Green Mountain Care Board of Vermont.

\section{RESULTS}

Table 1 shows the number and percentage of children (aged 0-21 years) with a medical claim attributed to a FP practice by year, child age (categories derived from Bright Futures Guidelines), ${ }_{17}$ sex, RUCA category for home location, and type of insurance. Percentages are in relation to $100 \%$ of children with claims to either a FP or PED primary care practice. The data suggest that the percentage of children attributed to a FP practice decreased from 2009 to 2016. The data in Table 1 show similar trends over time within categories of the child demographic variables as well. The changes over the years were tested in multiple regression models controlling for the other covariates. Over the study period, we found the average distribution of children to be: urban $(39 \%)$, large town $(20 \%)$, small town $(16 \%)$, and isolated rural (25\%). This is consistent with the US Census identification of most of Vermont residents living in rural areas. ${ }^{18}$

All covariates included in the generalized estimating equation multiple regression model were significantly associated with attribution to a FP practice $(P<.001)$. In any given year, children had $5 \%$ less odds of attending a FP than PEDS practice compared with the year before, controlling for child demographics (age, sex, RUCA category, and type of insurance), and accounting for the correlation among repeated child observations over 8 years $(\mathrm{OR}=0.95,95 \% \mathrm{CI}, 0.94-0.95)$. In this adjusted model, the child demographic variables independently predicted attending a FP practice. Females, compared

Table 1. Characteristics of Children Having at Least 2 Years With a Medical Claim Attributed to a Family Physician Practice

\begin{tabular}{|c|c|c|c|c|c|c|c|c|}
\hline \multirow[b]{2}{*}{ Characteristics } & \multicolumn{8}{|c|}{ Year, No. $(\%)^{a}$} \\
\hline & 2009 & 2010 & 2011 & 2012 & 2013 & 2014 & 2015 & 2016 \\
\hline & $36,660(36)$ & $36,977(36)$ & $37,045(36)$ & $36,776(35)$ & $34,372(34)$ & $33,444(34)$ & $31,041(32)$ & $25,407(32)$ \\
\hline \multicolumn{9}{|l|}{ Age } \\
\hline $0-11 \mathrm{~m}$ & $2,554(26)$ & $2,577(27)$ & $2,511(26)$ & $2,396(24)$ & $2,171(23)$ & $2,224(23)$ & $1,979(21)$ & 796 (19) \\
\hline $1-4 y$ & $5,426(27)$ & $5,426(26)$ & $5,441(26)$ & $5,357(26)$ & $4,786(25)$ & $4,604(24)$ & $4,078(22)$ & $3,470(21)$ \\
\hline $5-10 y$ & $8,315(30)$ & $8,388(30)$ & $8,270(29)$ & $8,254(29)$ & $7,591(27)$ & $7,505(27)$ & $6,967(25)$ & $5,914(25)$ \\
\hline $11-21$ y & $20,365(47)$ & $20,586(47)$ & $20,823(47)$ & $20,769(47)$ & $19,824(46)$ & $19,111(45)$ & $18,017(43)$ & $15,227(43)$ \\
\hline \multicolumn{9}{|l|}{ Sex } \\
\hline Male & $17,923(35)$ & $18,088(35)$ & $18,289(35)$ & $17,957(34)$ & $16,739(33)$ & $16,244(33)$ & $15,184(31)$ & 12,251 (30) \\
\hline Female & $18,737(37)$ & $18,889(37)$ & $18,756(37)$ & $18,819(37)$ & $17,632(36)$ & $17,200(35)$ & $15,857(33)$ & $13,156(33)$ \\
\hline \multicolumn{9}{|l|}{ Home location } \\
\hline Urban & $10,510(24)$ & $10,620(24)$ & $10,610(24)$ & $10,901(24)$ & $10,512(24)$ & $10,436(24)$ & $10,432(24)$ & $8,483(25)$ \\
\hline Large town & $7,528(41)$ & $7,627(41)$ & $7,565(41)$ & 7,261 (39) & $6,758(36)$ & $6,549(35)$ & $6,258(34)$ & $5,174(34)$ \\
\hline Small town & $5,853(38)$ & $5,815(38)$ & $5,879(37)$ & $5,825(37)$ & $5,111(37)$ & $4,927(36)$ & $4,157(31)$ & $3,273(29)$ \\
\hline Isolated rural & $12,769(53)$ & $12,915(53)$ & $12,991(53)$ & $12,789(52)$ & $11,991(52)$ & $11,532(50)$ & $10,194(44)$ & $8,477(43)$ \\
\hline \multicolumn{9}{|l|}{ Insurance } \\
\hline Non-Medicaid & $16,135(33)$ & $15,598(32)$ & $15,611(33)$ & $15,391(33)$ & $14,610(32)$ & $13,818(31)$ & $12,606(30)$ & $8,570(30)$ \\
\hline Medicaid & $20,525(39)$ & $21,379(39)$ & $21,434(39)$ & $21,385(38)$ & $19,762(37)$ & $19,626(36)$ & $18,435(33)$ & $16,837(32)$ \\
\hline
\end{tabular}


Table 2. Regression Results for Children Having at Least 2 Years With a Medical Claim

\begin{tabular}{|c|c|c|c|c|c|c|c|c|c|c|c|c|}
\hline \multirow[b]{2}{*}{ Characteristic } & \multicolumn{3}{|c|}{$\begin{array}{c}\text { Urban } \\
(n=81,141)\end{array}$} & \multicolumn{3}{|c|}{$\begin{array}{l}\text { Large Town } \\
(\mathrm{n}=37,031)\end{array}$} & \multicolumn{3}{|c|}{$\begin{array}{l}\text { Small Town } \\
(\mathrm{n}=31,383)\end{array}$} & \multicolumn{3}{|c|}{$\begin{array}{l}\text { Isolated Rural } \\
(\mathrm{n}=49,188)\end{array}$} \\
\hline & OR & $\begin{array}{c}P \\
\text { Value }\end{array}$ & $95 \% \mathrm{Cl}$ & OR & $\begin{array}{c}P \\
\text { Value }\end{array}$ & $95 \% \mathrm{Cl}$ & OR & $\begin{array}{c}P \\
\text { Value }\end{array}$ & $95 \% \mathrm{Cl}$ & OR & $\begin{array}{c}P \\
\text { Value }\end{array}$ & $95 \% \mathrm{Cl}$ \\
\hline Age $(0-21$ yr) & 1.11 & $<.001$ & $1.11-1.12$ & 1.13 & $<.001$ & $1.12-1.13$ & 1.09 & $<.001$ & $1.09-1.10$ & 1.09 & $<.001$ & $1.09-1.10$ \\
\hline $\begin{array}{l}\text { Sex (Reference }= \\
\text { males) }\end{array}$ & 1.13 & $<.001$ & $1.10-1.16$ & 1.03 & 0.15 & 0.99-1.07 & 1.03 & 0.25 & $0.98-1.07$ & 0.98 & 0.19 & $0.94-1.01$ \\
\hline Year & 0.97 & $<.001$ & $0.97-0.97$ & 0.94 & 0.16 & $0.94-0.94$ & 0.93 & $<.001$ & $0.93-0.93$ & 0.92 & $<.001$ & $0.92-0.92$ \\
\hline $\begin{array}{l}\text { Medicaid insurance } \\
\text { (Reference = } \\
\text { non-Medicaid) }\end{array}$ & 1.20 & $<.001$ & $1.18-1.22$ & 0.94 & $<.001$ & $0.91-0.97$ & 1.09 & $<.001$ & $1.05-1.12$ & 1.04 & .001 & $1.02-1.07$ \\
\hline
\end{tabular}

with males, had $5 \%$ greater odds of attending a FP practice $(\mathrm{OR}=1.05,95 \% \mathrm{CI}, 1.03-1.07)$. Children with Medicaid, compared with children with other insurance, had $9 \%$ greater odds of attending a FP practice $(\mathrm{OR}=1.09,95 \% \mathrm{CI}, 1.07-1.10)$. For each year increase in age, children had $11 \%$ greater odds of attending a FP practice $(\mathrm{OR}=1.11,95 \% \mathrm{CI}, 1.10-1.11)$. We wondered if these findings were influenced by including young adults (aged 19 to 21 years) in the sample. Thus, we conducted a sensitivity analysis of children aged 0 to 18 years and found results of similar magnitude, direction, and significance. Children living in nonurban areas, compared with urban areas, had greater odds of attending a FP practice when living in large towns $(\mathrm{OR}=1.54,95 \% \mathrm{CI}$, 1.51-1.57), small towns $(\mathrm{OR}=1.45,95 \% \mathrm{CI}, 1.42-1.48)$, and isolated rural areas $(\mathrm{OR}=1.96,95 \% \mathrm{CI}, 1.93-2.00)$.

In investigating the moderating effects of rurality on our primary associations of interest, we found significant interactions between RUCA and all covariates in the model $(P<.02)$. Detailed results from the same generalized estimating equation model stratified into 4 RUCA categories are shown in Table 2. The effect of calendar year on attending a FP practice was largest in the isolated rural RUCA areas, where for every 1 year increase, children living in isolated rural areas had an $8 \%$ lower odds of attending a FP practice. Regarding RUCA interactions among the demographic variables, the odds for age over all 4 RUCA categories were significant, with a somewhat more pronounced association for residence in urban areas or large towns. For sex, the association between sex and attending a FP practice was only significant for residence in the urban areas, with females from urban areas having a 13\% greater odds of attending a FP than a PED practice. The odds of children with Medicaid, as opposed to private insurance coverage, attending a FP over a PED practice was also highly associated with living in urban areas, although significant smaller associations in either direction also were present in large towns and small towns.

\section{DISCUSSION}

This longitudinal, population-based analysis of the child population in Vermont for the years 2009-2016 adds substantially to our understanding of the state of FP vs PED practice for child health care. This study confirms the findings of previous studies and yields new information about the influence of the rurality of the child's residence and of child's age, sex, and insurance status on the type of practice they are receiving primary preventative medical care from.

This study's finding of a $5 \%$ overall lower odds of attending a FP practice over time, controlling for confounders, verifies previous findings ${ }^{4,19}$ of a temporal trend of child visits moving from FP to PED practices. Others have delved into the reasons for this overall trend $\mathrm{d}^{1,3,4,20,21}$ and its implications, and we will not add to those speculations. The evidence shown in Table 2 that this trend varied according to the rurality of children's address, with decreasing odds of attending a FP practice associated with increasing rurality of residence, runs counter to the American Board of Family Medicine survey finding ${ }^{20}$ that rural FPs were more likely than counterparts to see pediatric patients. However, that latter finding was based on the location of the FP, whereas the present findings are based on the location of children's residence.

There are several possibilities for the shift in practice type of children's primary care. The number of children initially establishing care with family physicians may be a reflection of the field's national decline in offering obstetric services. ${ }^{22,23}$ Analysis of the National Ambulatory Medical Care Survey data, however, suggested the decreased role of FPs providing prenatal care was not accompanied by a similar drop in provision of well-child care to children younger than 2 years. ${ }^{5}$ It is possible children and families new to Vermont and looking to establish primary care preferentially choose PED practices because they are accepting children as new patients. In 2010, Vermont had the 
second highest state median age, ${ }_{1}^{24}$ and FP practices may have a higher caseload of older adults and thus not room in their practice for younger children. Projected shortfalls in the primary care workforce to address more complex, chronic ambulatory care needs of older individuals may divert resources from children's primary care ${ }^{25}$ and is worthy of further study.

A recent report on Vermont's health care workforce offers insight into this shift from FPs to PEDs. There has been a steady decrease in FP numbers, and fewer FPs (81\%) than PEDs (97\%) are accepting new patients. ${ }^{26} \mathrm{~A}$ shortage in adult primary care clinicians in rural areas may decrease access for pediatric patients in those FP practices. In our study, we found that for every year of increase in age children were $11 \%$ to $13 \%$ more likely to attend an FP practice in more urban areas, whereas in more rural areas they were only $9 \%$ more likely. This particular finding may be most generalizable to states where the numbers of FPs and PEDs are adequate.

The association of increasing child age with likelihood of attending a FP practice has been described previously in the National Ambulatory Medical Care Survey analyses and is readily understood, as research on adolescents suggests that they are more comfortable in settings appropriate for their age. ${ }^{27}$ The finding that females are more likely to receive care in a FP practice, and that this finding is largely driven by an association with patients' urban residence, is novel. Unfortunately, our data set did not allow us to query for the sex of the practitioners within FP or PED practices to investigate whether this was driven in some way by the sex of the clinicians within practices. This seems unlikely, however, as in the years of our study, the number of female primary care clincians in Vermont grew by $69 \%$, compared with $9 \%$ for males, ${ }^{26}$ and other data suggest that this has occurred equally among FPs and PEDs. The National Ambulatory Medical Care Survey data could be analyzed to assess the association between patient sex and type of primary care physician to assess whether this finding is applicable more widely.

The association of FP practice over PED practice among patients covered by Medicaid, largely attributable to families living in more urban areas, is challenging to explain, and runs counter to the higher concentration of PED practices in urban areas. This finding contradicts a separate data source of selfreported capacity in Vermont to accept new patients when considering insurance status, with FPs accepting smaller proportion (73\%) with Medicaid compared with PEDs (97\%). ${ }^{26}$ One possible explanation, although beyond the scope of this analysis, is that FP practices are also more prevalent in more urban areas, and that access to care for parents who themselves are covered by Medicaid is easier, translating to more pediatric visits to those practices. Beyond the potential convenience of parent and child being seen the same day, it is possible that FP practices that maintain acceptable access to parents with Medicaid are also those that maintain their pediatric clientele over time.

\section{Limitations}

In spite of the unique opportunities and advantages offered by Vermont as a model for investigating our research question, it is also possible that what happens in a rural New England state with a small population is not generalizable to the rest of the nation. Similar studies using the all-payer claims database, however, could run similar analyses based on the method of attribution described herein. Research using the all-payer claims database is known for potential problems, including mislabeling of activity. ${ }^{28}$ Our algorithm for practice attribution relied on codes selected by clinicians, who may have coded erroneously when multiple clinical issues arose in one visit. Primary care sought outside Vermont, or for which there is no medical claim submitted, is not part of this analysis. Finally, a drop in the number of claims submitted to the Vermont Health Care Uniform Reporting and Evaluation System occurred in the final year of analysis, which coincided with a decision by some payers not to submit data, although no evidence suggests that payers preferentially reported on patients of distinct age, sex, or home location. Across the claim years examined, the average number of children we attributed to clincians was within $2 \%$ of the 2010 US Census. ${ }^{29}$

\section{CONCLUSIONS}

In this study, we used medical claims data to determine whether the proportion of children at the population level seen at FP and PED practices was changing over time, how patient demographics influenced any change, and whether identified associations varied by the rurality of patient residence. Our analysis confirmed the temporal trend from FP to PED practices noted in survey studies, and suggested a new finding related to an enhanced trend toward PED practices among children living in rural areas. This will need to be confirmed by research in other settings.

To read or post commentaries in response to this article, see it online at http://www.AnnFamMed.org/content/17/5/390.

Submitted October 22, 2018; revised, March 1, 2019; accepted March 26, 2019.

Key words: child health; pediatricians; physicians, family; primary health care; workforce

Previous presentations: Academic Pediatric Association Region I Meeting; March 26, 2018; Waltham, Massachusetts; and the Pediatric Academic Societies Meeting; May 5-8, 2018; Toronto, Ontario, Canada. 
Disclaimer: The analyses, conclusions, and recommendations from these data are solely those of the study authors, and are not necessarily those of the Green Mountain Care Board (GMCB). The GMCB had no input into the study design, implementation, or interpretation of the findings. The conclusions are those of the authors alone, and no official endorsement by the GMCB was intended or should be inferred.

Supplemental materials: Available at http://www.AnnFamMed. org/content/17/5/390/suppl/DC1/.

\section{References}

1. Phillips RL Jr, Bazemore AW, Dodoo MS, Shipman SA, Green LA. Family physicians in the child health care workforce: opportunities for collaboration in improving the health of children. Pediatrics. 2006;118(3):1200-1206.

2. Freed GL, Dunham KM, Gebremariam A, Wheeler JR, Research Advisory Committee of the American Board of Pediatrics. Which pediatricians are providing care to America's children? An update on the trends and changes during the past 26 years. J Pediatr. 2010; 157(1):148-152 e141.

3. Phillips RL Jr, Dodoo MS, McCann JL, et al. Report to the Task Force on the Care of Children by Family Physicians. Washington, DC: Robert Graham Center; 2005.

4. Bazemore AW, Makaroff LA, Puffer JC, et al. Declining numbers of family physicians are caring for children. J Am Board Fam Med. 2012;25(2):139-140.

5. Cohen D, Coco A. Trends in well-child visits to family physicians by children younger than 2 years of age. Ann Fam Med. 2010;8(3):245-248.

6. Shipman SA, Lan J, Chang CH, Goodman DC. Geographic maldistribution of primary care for children. Pediatrics. 2011;127(1):19-27.

7. Cooley WC, Sagerman PJ; American Academy of Pediatrics; American Academy of Family Physicians; American College of Physicians; Transitions Clinical Report Authoring Group. Supporting the health care transition from adolescence to adulthood in the medical home. Pediatrics. 2011;128(1):182-200.

8. Ashman JJ, Rui P, Okeyode T. Characteristics of office-based physician visits, 2015. NCHS Data Brief. 2018;(310):1-8.

9. Finison K, Mohlman M, Jones C, et al. Risk-adjustment methods for all-payer comparative performance reporting in Vermont. BMC Health Serv Res. 2017;17(1):58.

10. Selden TM. Compliance with well-child visit recommendations: evidence from the Medical Expenditure Panel Survey, 2000-2002. Pediatrics. 2006;118(6):e1766-e1778.

11. Hing E, Hsiao (-J, National Center for Health Statistics. State variablity in supply of office-based primary care providers: 2012. NCHS Data Brief. 2014;(151):1-8,

12. US Department of Health and Human Services, Health Resources and Services Administration, Maternal and Child Health Bureau. The Health and Well-being of Children in Rural Areas: A Portrait of the Nation, 2011-2012. Rockville, MD: US Department of Health and Human Services; 2015.

13. Christensen AL, Zickafoose JS, Natzke B, McMorrow S, Ireys HT. Associations between practice-reported medical homeness and health care utilization among publicly insured children. Acad Pediatr. 2015;15(3):267-274.
14. Smith ML, Dickerson JB, Wendel ML, et al. The utility of rural and underserved designations in geospatial assessments of distance traveled to healthcare services: Implications for public health research and practice. J Environ Public Health. 2013:960157.

15. Morrill R, Cromartie J, Hart G. Metropolitan, urban, and rural commuting areas: Toward a better depiction of the United States settlement system. Urban Geogr. 2013;20(8):727-748.

16. Washington State Department of Health. Guidelines for using rural-urban classification systems for community health assessment. https://www.doh.wa.gov/Portals/1/Documents/1500/RUCAGuide. pdf. Published Oct 27, 2016.

17. Bright Futures: Guidelines for Health Suprevision of Infants, Children, and Adolescents. 4 ed. Elk Grove Village, IL: American Academy of Pediatrics; 2017.

18. United States Census Bureau. Results for Urban and Rural Population Distribution. In: 2010 Census Congressional District Summary File. https://factfinder.census.gov/faces/tableservices/jsf/pages/product view.xhtml?pid=DEC_10_115_P2EprodType = table. Published May 26, 2011. Updated Aug 25, 2011. Accessed Feb 22, 2018.

19. Freed GL, Nahra TA, Wheeler JR. Which physicians are providing health care to America's children? Trends and changes during the past 20 years. Arch Pediatr Adolesc Med. 2004;158(1):22-26.

20. Makaroff LA, Xierali IM, Petterson SM, Shipman SA, Puffer JC, Bazemore AW. Factors influencing family physicians' contribution to the child health care workforce. Ann Fam Med. 2014;12(5):427-431.

21. Shipman SA. Family physicians closing their doors to children: considering the implications. J Am Board Fam Med. 2012;25(2):141-142.

22. Tong ST, Makaroff LA, Xierali IM, Puffer JC, Newton WP, Bazemore AW. Family physicians in the maternity care workforce: factors influencing declining trends. Matern Child Health J. 2013;17(9):1576-1581.

23. Weidner AKH, Chen FM. Changes in preparation and practice patterns among new family physicians. Ann Fam Med. 2019;17(1): 46-48.

24. United States Census Bureau. American FactFinder - Results for Age Groups and Sex: 2010. In: 2010 Census Summary File 1. https://fact finder.census.gov/faces/tableservices/jsf/pages/productview.xhtml? pid=DEC_10_SF1_QTP1EprodType=table. Published May 26, 2011. Updated Aug 25, 2011. Accessed Feb 22, 2018.

25. Petterson SM, Liaw WR, Phillips RL Jr, Rabin DL, Meyers DS, Bazemore AW. Projecting US primary care physician workforce needs: 2010-2025. Ann Fam Med. 2012;10(6):503-509.

26. Vermont Department of Health. 2016 Physician Census Statistical Report. http://www.healthvermont.gov/sites/default/files/documents/ PDF/phys16bk.PDF. Published Nov 2017.

27. Ambresin A-E, Bennett K, Patton GC, Sanci LA, Sawyer SM. Assessment of youth-friendly health care: a systematic review of indicators drawn from young people's perspectives. J Adolesc Health. 2013; 52(6):670-681.

28. van Walraven C, Austin P. Administrative database research has unique characteristics that can risk biased results. J Clin Epidemiol. 2012;65(2):126-131.

29. United States Census Bureau. American FactFinder - Results for Single Years of Age and Sex. In: 2010 Census Summary File 1. https:// factfinder.census.gov/faces/tableservices/jsf/pages/productview. xhtml?pid=DEC_10_SF1_QTP2\&prodType=table. Published May 26, 2011. Updated Aug 25, 2011. Accessed Feb 22, 2018. 